\title{
Pyriproxyfen, a juvenoid hormone analog, does not induce male production in parthenogenetic lineages of Eucypris virens (Crustacea: Ostracoda)
}

\author{
Jochen VANDEKERKHOVE ${ }^{1,2) *}$ Giampaolo ROSSETTI $^{1)}$ and Francesc MEZQUITA ${ }^{2)}$ \\ ${ }^{1)}$ Department of Environmental Sciences, University of Parma, Viale G. P. Usberti, 11A, 43100 Parma, Italy \\ ${ }^{2)}$ Department of Microbiology and Ecology, University of València, C/ Doctor Moliner 50, 46100 Burjassot, València, Spain \\ *e-mail corresponding author: jovan@uv.es
}

\begin{abstract}
Analogs of juvenoid hormones are increasingly recommended for controlling insect pests in agriculture. One of these analogs, pyriproxyfen, was found to be very potent in inducing male production in Daphnia under laboratory conditions, even after acute exposure. Other studies also demonstrated a major role of juvenoid hormones for the sex determination in arthropods that have sex chromosomes. We exposed parthenogenetic lineages of the freshwater ostracod Eucypris virens to a wide range of pyriproxyfen concentrations, and compared mortality and fecundity between treated and control animals. Animals exposed to the highest concentrations of pyriproxyfen (3-30 nM) experienced a higher mortality than control animals, but no treatment effects were found on the production rates of eggs and hatchlings. Also, hatchlings that emerged from eggs deposited by treated individuals did not suffer from an increased mortality rate. No males were found among the 91 hatchlings that could be grown to adulthood. These results suggest that previous observations of a reduced population growth of ostracods in treated field crops might not be due to an alteration of the sex ratio, but rather to an increased mortality of the exposed females.
\end{abstract}

Key words: Pyriproxyfen, juvenoid hormones, male induction, geographic parthenogenesis, Ostracoda

\section{INTRODUCTION}

Recent experimental research revealed that juvenoid hormones regulate sex determination in different arthropod groups, including cladocerans (Olmstead \& LeBlanc 2002, 2003; Tatarazako et al. 2003; Rider et al. 2005; Kim et al. 2006; Oda et al. 2006) and aphids (Hales \& Mittler 1987, 2005). For species where males were previously unknown, a whole range of new diagnostic characters could be obtained through application of a hormone treatment (Kim et al. 2006). The study of these characters may lead to new taxonomic and phylogenetic insights. The possibility to 'resurrect' males in parthenogenetic populations also provides a tool for studying the conservation of traits that are hidden to natural selection (Minelli \& Fusco 2006).

Methylfarnesoate is a crustacean juvenoid hormone that acts through the same signalling pathway as haemoglobin induction (Rider et al. 2005). The hormone induced male production in lineages that were considered as non-male producers (Rider et al. 2005), and even in species for which males were not known (Kim et al. 2006). Several synthetic analogs of methylfarnesoate, namely pyriproxyfen, methoprene and fenoxycarb, were found to have similar sex determining effects (Olmstead \& LeBlanc 2003; Rider et al. 2005). In particular, pyriproxyfen proved to be very powerful. Exposure of gravid Daphnia to a pyriproxyfen concentration of $0.3 \mathrm{nM}$ resulted in the production of $80 \%$ males, whereas a similar proportion of male neonates was only observed for Daphnia reproducing in an $800 \mathrm{nM}$ methylfarnesoate solution (Olmstead \& LeBlanc 2003). Pyriproxyfen is widely used in agriculture as a pesticide. It is mainly applied to terrestrial environments, for example to control white fly on cotton and scale insects on trees (Center of Integrated Pest Management 2002, in Olmstead \& LeBlanc 2003), after which it may leach into aquatic systems. The pesticide is also applied directly to aquatic environments against mosquitos in rice fields (Hopkins 1994).

In cyclically parthenogenetic cladocerans, sex is determined environmentally, with males appearing at high population densities, low food concentrations and decreasing temperatures (Hobæk \& Larsson 1990; Kleiven et al. 1992). Juvenoid hormones are the endocrine factors that transduce these proximate stimuli to the physiological response. Although there is no evidence available for the existence of sex chromosomes in Eucypris virens (Jurine 1820) (Crustacea, Ostracoda), sex is commonly believed to be genetically determined in this species, like in many other freshwater ostracods (Bauer 1940; Dietz 1958). Asexual lineages may still possess the genes needed for the development of males, as in freshwater ostracods transitions from sexual to asexual reproduction are quite common (Chaplin et al. 1994). Juvenoid hormones may be able to trigger the machinery required for male development, just like they are able to trigger the production of males in cladoceran lineages that have probably been asexual for many thousands of years (Kearney 2005). The mechanism in ostracods could be similar to the one observed in aphids, which also have genetic sex determination. In aphids, 


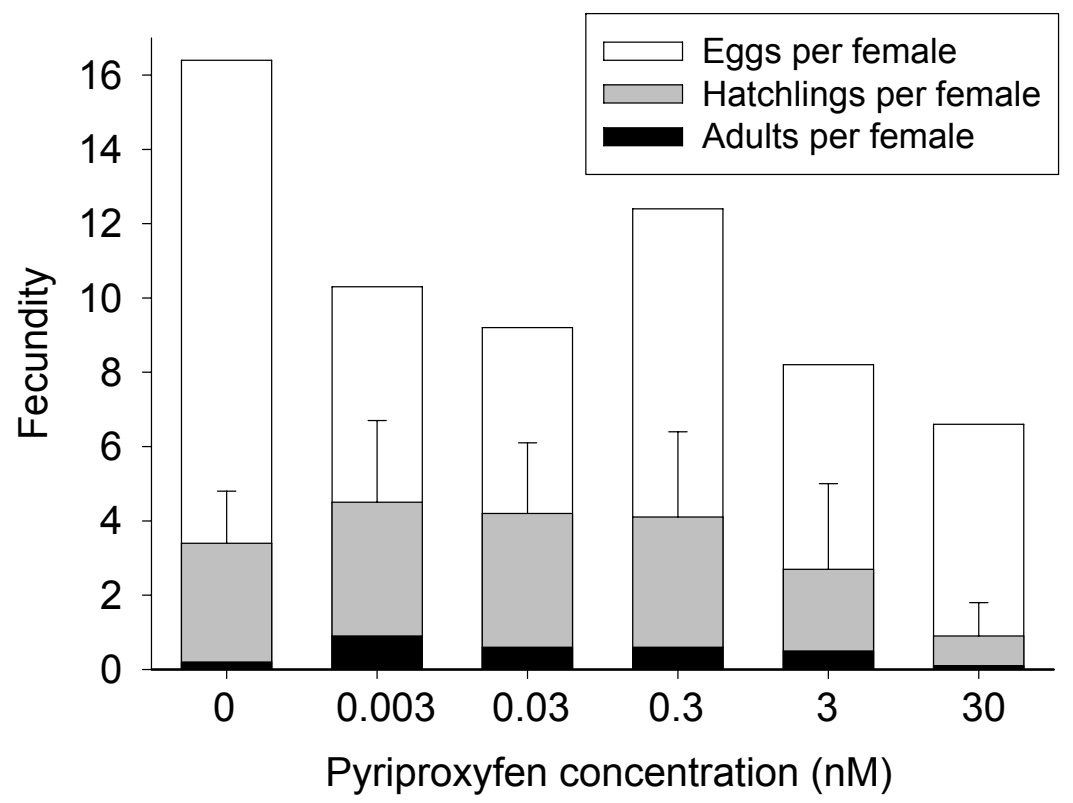

Fig. 1. Fecundity, measured as the number of eggs, hatchlings and adults produced during a 15 day exposure period of parthenogenetic females of Eucypris virens to varying concentrations of pyriproxyfen. Bars show means of three replicates, error bars show upper limits of the $95 \%$ CI of the hatchling production rates.

absence of juvenile hormone favours parthenogenesis through the loss of one of the sex chromosomes (Hales \& Mittler 1987).

Here, we test for the effects of different concentrations of pyriproxyfen on the fecundity of obligate parthenogenetic lineages of $E$. virens, and check for the existence of a sex-determining effect.

\section{METHODS}

Parthenogenetic females of the geographic parthenogen $E$. virens were collected in Rivalazzetto, a temporary pond near Parma (Emilia Romagna, Italy). Males are absent in this population. Adults were sorted out and batches of 10 individuals were transferred to $50 \mathrm{ml}$ jars filled with mineral water and varying concentrations of pyriproxyfen: $0 \mathrm{nM}, 0.003 \mathrm{nM}, 0.03 \mathrm{nM}, 0.3 \mathrm{nM}, 3 \mathrm{nM}$ and $30 \mathrm{nM}$. This range covers the concentrations that are known to induce male production in Daphnia (Olmstead \& LeBlanc 2003; Rider et al. 2005) and includes the doses applied to rice fields (Hopkins 1994). The medium was renewed every four days. Pyriproxyfen was dissolved in ethanol. Ethanol concentrations did not differ between control jars $(0 \mathrm{nM}$ pyriproxyfen; $0.5 \% \mathrm{v} / \mathrm{v}$ ethanol) and treatment jars $(0.003-30 \mathrm{nM}$ pyriproxyfen; $0.5 \% \mathrm{v} / \mathrm{v}$ ethanol). A $0.5 \% \mathrm{v} / \mathrm{v}$ ethanol solution does not affect sex ratios of D. magna offspring (Olmstead \& LeBlanc 2003). There were three replicate jars per treatment. Survivors and deposited eggs were counted after 1, 3, 7 and 15 days, and transferred to 50 $\mathrm{ml}$ jars filled with untreated mineral water. Hatchlings were counted twice a week, upon renewal of culture medium and food. As food a mixture of spinach and the cyanobacterium Tolypothrix tenuis was provided
(Schmit et al. 2007). Adult offspring were sexed by microscopic investigation of reproductive organs.

Survival curves were compared among treatments using Kaplan Meier's method, which allows for the inclusion of censored cases (living individuals at the end of the experiment). One-sided Dunnett $t$-tests were used to compare the fecundity parameters (egg production rate, hatchling production rate and number of adult offspring) between control animals and animals treated with pyriproxyfen. The assumptions of normally distributed data and homogeneity of variances were tested for with the Kolmogorov-Smirnov test and the Bartlett test, respectively. All statistics were computed with Statistica 6.0 (Statsoft Inc. 2003).

\section{RESULTS}

The parental animals experienced a relatively high mortality (on average $6 \%$ mortality day ${ }^{-1}$ ). Analysis of the survival curves indicated that mortality rates were treatment specific (Kaplan-Meier: $\chi^{2}=15.5, \mathrm{df}=5, p=$ $0.008)$. In the three jars with the highest concentration of pyriproxyfen, all females were recorded dead on day 15 , when in the other jars there were still up to seven animals alive.

Of the 1897 eggs that were deposited, 593 hatched. Of these, 91 could be grown to adulthood and all were identified as females. Despite the increased mortality of animals treated with high concentrations of pyriproxyfen, and a trend towards decreasing fecundity with increasing pyriproxyfen concentrations (Fig. 1), none of the pyriproxyfen treatments reduced significantly the fecundity of the females when compared with control animals (Dunnett's tests: $\mathrm{df}=12, p>0.05$ ). Patterns may 
be obscured by the high variation in fecundity that was observed among replicates. For example, females exposed to a pyriproxyfen concentration of $0.3 \mathrm{nM}$ produced in one jar on average 26.2 eggs, whereas only 5.3 eggs were produced by females from another jar.

\section{DISCUSSION}

Species capable of both sexual and asexual reproduction often show a distinct geographic pattern of the distribution of the two types of reproduction. Typically, asexuals cover a larger geographic range than their conspecific sexual relatives (geographic parthenogenesis; Vandel 1928). Several attempts have been made to document the distributions of the different modes of reproduction (e.g. Horne et al. 1998; Hebert \& Finston 2001). The ultimate goal is to find causal relationships with environmental gradients. Recent findings of juvenoid hormone analogs capable of inducing male production in parthenogenetic lineages suggest that observed patterns may have to be interpreted with caution, as some of these analogs are applied as pesticides on a large scale. As such, regional differences in agricultural practices may interfere with natural phenomena regulating the distribution of males in geographic parthenogens. So far, the presence of males has not been linked directly to the use of pesticides. The only field study comparing non-target invertebrate assemblages in treated and untreated crops focussed on community dynamics, without reporting on effects on sex ratios (Schaefer \& Miura 1990). These authors found a minor but significant impact of the use of pyriproxyfen on the dynamics of cladoceran and ostracod communities. Our results suggest that, at least for ostracods, this was not due to the induction of males, but probably to an increased mortality rate of the animals exposed to the pesticide.

It remains to be examined if sex ratios of cladoceran assemblages are artificially altered in natural populations through agricultural use of juvenoid hormone analogs. Schaefer \& Miura (1990) treated rice field plots with pyriproxyfen in doses that were 8-20 times higher than those commonly applied to field crops. Shortly after application, the doses found in the water did not exceed $0.18 \mathrm{nM}$, which is close to the lower limit for inducing male production in D. magna (i.e. 0.3 nM; Olmstead \& LeBlanc 2003). However, depending on the amount of organic matter, pyriproxyfen may remain present up to two months (Schaefer et al. 1988) and concentrations may accumulate through the food chain (Muñoz et al. 1996). The potential for bioaccumulation of pyriproxyfen is high, given its low solubility in water and preferential accumulation in tissues rich in lipids (Fujisawa et al. 2002: $\log \mathrm{Kow}_{\text {pyriproxyfen }}=$ 5.37). Therefore, the concentrations measured in treated plots by Schaefer \& Miura (1990), in combination with the observed direct and strong effects of pyriproxyfen on cladocerans, are perturbing. Artificial increases of male proportions in cladocerans will reduce the natural potential for population growth, mainly because males do not contribute directly to the production of new offspring (Maynard Smith 1978; Innes et al. 2000). Also, in most cladocerans, sexual reproduction is associated with the production of resting eggs. These resting eggs are encapsulated in ephippia that usually contain only one or two eggs, whereas unfertilised eggs are produced in higher numbers and do not need a desiccation or hibernation period before hatching (Innes 2004). Increased male proportions limit population growth on the short term, an effect that may rapidly escalate throughout the entire food web via bottom-up and topdown effects (Carpenter \& Kitchell 1993).

In conclusion, our data indicate that juvenoid hormone analogs do not interfere with sex determination in parthenogenetic lineages of $E$. virens. This finding contrasts with that of recent studies on cladocerans and aphids, and raises the question how sex determination differs among arthropod groups.

\section{ACKNOWLEDGMENTS}

This work was funded by the EU Marie Curie Research Training Network SexAsex (From Sex to Asex: a case study on interactions between sexual and asexual reproduction, contract MRTN-CT-2004512492). We are very grateful to all members of the network for their practical contributions to the work presented here and for many stimulating discussions.

\section{REFERENCES}

Bauer, H. 1940. Über die Chromosomen der bisexuellen und der parthenogenetischen Rasse des Ostracoden Heterocypris incongruens RAMD. Chromosoma, 1: 620-637.

Carpenter, S.R. \& J.F. Kitchell (Eds). 1993. The trophic cascade in lakes. Cambridge University Press, Cambridge, England.

Center of Integrated Pest Management. 2002. North Carolina agricultural chemicals manual. Raleigh, North Carolina.

Chaplin, J.A., J.E. Havel \& P.D.N. Hebert. 1994. Sex and ostracods. Trends Ecol. Evol., 12: 298-299.

Dietz, R. 1958. Multiple Geschlechtschromosomen bei den cypriden Ostracoden, ihre Evolution und ihr Teilungsverhalten. Chromosoma, 9: 359-440.

Fujisawa, T., K. Ichise, M. Fukushima, T. Katagi \& Y. Takimoto. 2002. Mathematical model of the uptake of nonionized pesticides by edible root of root crops. Nippon Noyaku Gakkaishi, 27: 242-248.

Hales, D.F. \& T.E. Mittler. 1987. Chromosomal sex determination in aphids controlled by juvenile hormone. Genome, 29: 107-109.

Hales, D.F. \& T.E. Mittler. 2005. Male production by aphids prenatally treated with precocene: Prevention by shortterm kinoprene treatment. Arch. Insect Biochem. Physiol., 7: 29-36.

Hebert, P.D.N. \& T.L. Finston. 2001. Macrogeographic patterns of breeding system diversity in the Daphnia pulex group from the United States and Mexico. Heredity, 87: 153-161.

Hobæk, A. \& P. Larsson. 1990. Sex determination in Daphnia magna. Ecology, 71: 2255-2268. 
Hopkins, W.L. 1994. Ag chemical new compound review. Thompson publications, Indianapolis: $465 \mathrm{pp}$.

Horne, D.J., A. Baltanás \& G. Paris. 1998. Geographical distribution of reproductive modes in living non-marine ostracods. In: K. Martens (Ed.), Sex and parthenogenesis: evolutionary ecology of reproductive modes in non-marine ostracods. Backhuys Publishers, Leiden: 77-100.

Innes, D.J. 2004. Sexual reproduction of Daphnia pulex in a temporary habitat. Oecologia, 111: 53-60.

Innes, D.J., C.J. Fox \& G.L. Winsor. 2000. Avoiding the cost of males in obligately asexual Daphnia pulex (Leydig). Proc. R. Soc. Lond. B, 267: 991-997.

Kearney, T.M. 2005. Hybridization, glaciation and geographical parthenogenesis. Trends Ecol. Evol., 20: 495-502.

Kim, K., A. Kotov \& D.J. Taylor. 2006. Hormonal induction of undescribed males resolves cryptic species of cladocerans. Proc. R. Soc. Lond. B, 273: 141-147.

Kleiven, O., P. Larsson \& A. Hobæk. 1992. Sexual reproduction in Daphnia magna requires three stimuli. Oikos, 65: 197-206.

Maynard Smith, J. 1978. The evolution of sex. Cambridge University Press, Cambridge, England.

Minelli, A. \& G. Fusco. 2006. Water-flea males from the netherworld. Trends Ecol. Evol., 21: 474-476.

Muñoz, M.J., C. Ramos \& J.V. Tarazona. 1996. Bioaccumulation and toxicity of hexachlorobenzene in Chlorella vulgaris and Daphnia magna. Aquat. Toxicol., 35: 211-220.

Oda, S., N. Tatarazako, H. Watanabe, M. Morita \& T. Iguchi. 2006. Genetic differences in the production of male neonates in Daphnia magna exposed to juvenile hormone analogs. Chemosphere, 63: 1477-1484.
Olmstead, A.W. \& G.A. LeBlanc. 2002. Juvenoid hormone methyl farnesoate is a sex determinant in the crustacean Daphnia magna. J. exp. Zool., 293: 736-739.

Olmstead, A.W. \& G.A. LeBlanc. 2003. Insecticidal juvenile hormone analogs stimulate the production of male offspring in the crustacean Daphnia magna. Environm. Health Persp., 111: 919-924.

Rider, C.V., T.A. Gorr, A.W. Olmstead, B.A. Wasilak \& G.A. LeBlanc. 2005. Stress signaling: coregulation of hemoglobin and male sex determination through a terpenoid signaling pathway in a crustacean. J. exp. Biol., 208: 15-23.

Schaefer, C.H. \& T. Miura. 1990. Chemical persistence and effects of S-31183, 2-[1-methyl-2-(4-phenoxyphenoxy) ethoxy]pyridine, on aquatic organisms in field-tests. $J$. econ. Entomol., 83: 1768-1776.

Schaefer, C.H., T. Miura, E. Dupras, F. Mulligan \& W. Wilder. 1988. Efficacy, nontarget effects, and chemical persistence of S-31183, a promising mosquito (Diptera: Culicidae) control agent. J. econ. Entomol., 83: 1768-1776.

Schmit, O., G. Rossetti, J. Vandekerkhove \& F. Mezquita. 2007. Food selection in Eucypris virens (Crustacea: Ostracoda) under experimental conditions. Hydrobiologia, 585: $135-140$

Statsoft Inc. 2003. Electronic Statistics Textbook. Tulsa, OK, Statsoft. Web: http://www.statsoft.com/textbook/stathome .html.

Tatarazako, N., S. Oda, H. Watanabe, M. Morita \& T. Iguchi. 2003. Juvenile hormone agonists affect the occurence of male Daphnia. Chemosphere, 53: 827-833.

Vandel, A., 1928. La parthénogénèse géographique. Bull. Biol. Fr. Belg., 62: 164-281.

Received: April 2007

Accepted: May 2007 